\title{
Knezovi krčki Frankapani kao „začinjavci”: Njemačko- rimski brevijar (1518.) Krste I. Frankapana
}

\section{Cvetnić, Sanja}

Source / Izvornik: Institucije povijesti umjetnosti : zbornik 4. kongresa hrvatskih povjesničara umjetnosti, 2019, 107 - 111

Conference paper / Rad u zborniku

Publication status / Verzija rada: Published version / Objavljena verzija rada (izdavačev PDF)

https://doi.org/10.31664/z4khpu.14

Permanent link / Trajna poveznica: https://urn.nsk.hr/urn:nbn:hr:254:274399

Rights / Prava: Attribution 4.0 International/Imenovanje 4.0 međunarodna

Download date / Datum preuzimanja: 2023-04-26

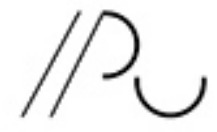

INSIIIUTZZA POVIJESTUMMETNOST
Repository / Repozitorij:

PODEST - Institute of Art History Repository

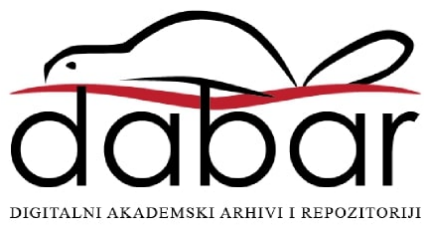




\section{Knezovi krčki Frankapani kao "začinjavci”: Njemačko-rimski brevijar (I5I8.) Krste I. Frankapana}

Uz češće navođene uloge u osnutku crkava i samostana, knezovi krčki Frankapani bili su svo vrijeme svoga postojanja pokretači humanističkih zasada, od kojih su neke opstale i kada je obitelj sišla s povijesne pozornice. Tijekom cijele svoje polustoljetne povijesti, u svim naraštajima njeguju pisanu riječ i vezani su za kulturu knjige: od čašćenja knjige kao relikvije (Kločev glagoljaš; lat. Glagolita Clozianus), narudžbe liturgijskih rukopisnih knjigā sa sitnoslikama uglednih mletačkih sitnoslikara (Drugi vrbnički misal) do pojava prvih tiskara. Frankapani se javljaju kao autori tiskanih govorā suprotiva Turkom u vrijeme osmanskih prodora (Krsto I. Frankapan I52I. i njegov otac Bernardin Frankapan Modruški I522., Vuk Frankapan Brinjski I53o. i Ivan X., redovnički Franjo, Frankapan Cetinski I54I.), kao osnivači škola i školskih zaklada u vrijeme kada je Hrvatska svedena na svoj najmanji opseg (polovinom I7. stoljeća), naručitelji poslijetridentskih molitvenika i prijevoda ne samo za govornike hrvatskoga, nego i mađarskoga, kao književni mecene, prevoditelji i pjesnici.

Zbog raskoši opreme s nekoliko stotina knjižnih ilustracija (drvorezi), za povijest umjetnosti posebno je važan Njemačkorimski brevijar ${ }^{1}$ što ga je Krsto I. Frankapan dao objaviti I5I8. godine, pred kraj mletačkih uzničkih dana, ${ }^{2}$ provedenih dijelom u društvu supruge Apolonije rođene Lang. U Hrvatskoj samo Nacionalna i sveučilišna knjižnica u Zagrebu od prije dva desetljeća posjeduje taj rijetki brevijar (naklada je iznosila 400 primjeraka), a prvi koji je o toj molitvenoj knjizi pisao u Hrvatskoj bio je Matija Mesić (1870.), prema primjerku iz Beča: „Jezik je tomu brevijaru onaj, što ga zovu neuhochdeutsche Schriftsprache, s riedkimi švabsko-alemanskimi osebinami. Prevodilicom će biti, veli se, po svoj prilici sama Apolonija, koja je kanoti rodjena Augsburžanka imala priliku, da u viših krugovih nauči onaj jezik, kojim je brevijar pisan; njezin pako prevod bit će u zaglavku pomenuti bosonožac Jakov Wig

\section{Sanja Cvetnić}

Odsjek za povijest umjetnosti

Filozofski fakultet

Sveučilište u Zagrebu

scvetnic@ffzg.hr

https://orcid.org/oooo-ooo2-0529-5229
I Deutsch-römisches Brevier (Frangipani-Brevier) Venecija, Gregorius de Gregoriis, „dausēt. v. hūdert uñ. xviij. iar am letstē dag dessz monatz Octobris” (3I. listopada I5I8.).

2 „Fol. 296. (6 detto [gennaio, to jest 6 . siječnja I5I9.]). In questa matina si parti il Conte Cristoforo Frangipani, stato preson in Toreselle zorni I8I3 (essendo stato fatto prigioniero sul principio del I5I4) [...].” MARINO SANUTO, Ragguagli sulla vita e sulle opere di Marin Sanuto detto il Juniore, veneto patrizio e cronista pregevolissimo de secoli XV, XVI. Intitolati dell'amicizia di uno straniero al nobile Jacopo Vincenzo Foscarini. Opera divisa in tre parti: Parte II, Venezia, Dalla Tipografia di Alvisopoli, I837., 236. 
izpravio i uredio.”3 Prema upozorenju Jeffreyja F. Hamburgera o važnosti ženske uloge u popularizaciji ilustriranih molitvenih knjiga, ${ }^{4}$ moguće je pretpostaviti udio Krstine supruge Apolonije i u odluci da se brevijar bogato likovno opremi, a tako i njegova namjena za žensku publiku (premda ne isključivo). ${ }^{5}$ Često su reproducirani drvorezi koji predstavljaju Krstu I. i Apoloniju: prvi se sastoji od grbova supružnika i pojavljuje se na početku, prije kalendara (fol. A2r), a drugi je otisnut nakon kalendara, kazala kratica, kazala psalama i sadržaja, a prije molitava i čitanja (fol. [B8v]), te ponovno na fol. $468 \mathrm{v}$. Na njemu su, na posebnom listu, prikazani kao poklekli zavjetnici podno prizora Krunidbe Bogorodice (sl. I), na kojemu je u dnu trona Boga Oca i potpis: „.3.A.”. Krstu I. i Apoloniju izrijekom

Slika I

Ioannes Andrea Vavassore, Krunidba Bogorodice, Krsto I. Frankapan i Apolonija Lang, u: Njemačko-rimski brevijar, Venecija, I518., fol. [B8v], foto: (c) Nacionalna i sveučilišna

knjižnica u Zagrebu, snimili Darko Čižmek i Sonja Hrelja

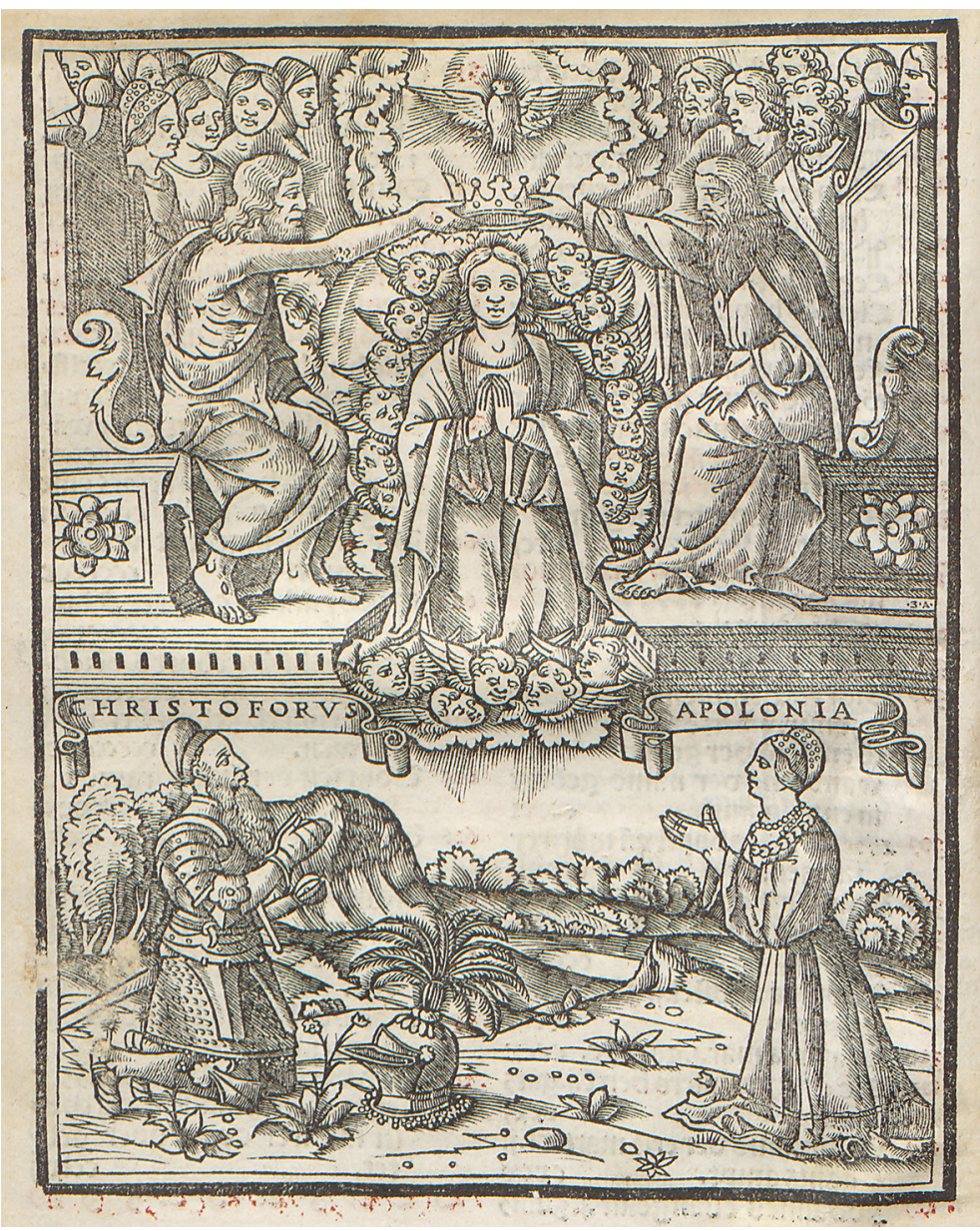

3 MATIJA MESiĆ, Krsto Frankopan u tudjini, u: Rad Jugoslavenske akademije znanosti $i$ umjetnosti, I3 (I870.), 77-79. Primjerak u Budimpešti (Narodni muzej) navodi MARIJA PANTELIĆ, Senjski Lobkowiczov glagoljski kodeks iz I359--prototip srednjevjekovnih „liber horarium” za laike, u: Senjski zbornik: prilozi za geografiju, etnologiju, gospodarstvo, povijest $i$ kulturu, I, VIII (I98I.), 366, bilj. I6. Marija Šercar ponavlja podatak o primjerku u Budimpešti i dodaje jedan u Heidelbergu. MARIJA ŠERCAR, Žene Frankopanke, u: Modruški zbornik, 4-5 (20II.), 49-5o. Primjerak Brevijara još posjeduje Universitätsbibliothek u Salzburgu (sign. F I 648); usp. ERNST VON FRISCH, Das Frangipani-Brevier und seine Geschichte, u: Salzburger Museumsblätter, 3, II (I923.), I-3. Primjerak u Bayerische Staatsbibliothek (sign. I395554 4 Liturg. I23 a) je digitaliziran: http://reader. digitale-sammlungen.de/de/fsi/object/display/ bsbıог64I99_ооог7.html (postavljeno 20. listopada 2oog.; pregledano 3. lipnja 2oI6.). U digitaliziranom primjerku numeracija teče do lista 452 , a onda se nastavlja s listom 6or, što je podudarno bečkom i zagrebačkom primjerku. Primjerak u Library of Congress u Washingtonu poznat je iz literature: FREDERICK R. GOFF, Rare books: Lessing J. Rosenwald Collection, u: Quarterly Journal of Current Acquisitions (Washington, Library of Congress), 3, IX (I952.), I63. Još dva moguća primjerka-od kojih je jedan možda otišao $\mathrm{u}$ Washington (spomenuti primjerak u Library of Congress?)-objavljena su u katalogu aukcijske kuće Gilhofer \& Ranschburg u Beču oko r93o. godine: The XVIth century: a large collection of valuable Books on all subjects printed from I5OI up to I6oo, mostly in their original bindings, Beč, Gilhofer \& Ranschburg, s. a. [oko I93o.]: Part I. Alchemy-History, br. IO2I i I022, 65. Primjerak u Nacionalnoj i sveučilišnoj knjižnici u Zagrebu ima signaturu RIIF-4 ${ }^{\circ}-36$ I (do listopada 2019. bio je zaveden pod signaturom RIIF- $8^{\circ}-\mathrm{I} 832$ ). Tijekom pripreme ovoga priloga Ivan Jurković (20I7.) objavio je detaljnu studiju s identifikacijom grbova i spomenom drugih sačuvanih primjeraka. Usp. IVAN JURKOVIĆ, O grbovima $u$ molitvenicima koje su I5ı8. u Veneciji dali tiskati Krsto Frankapan sa suprugom Apolonijom Lang i I56o. u Padovi Katarina Frankapan, supruga Nikole Zrinskoga Sigetskoga, u: Zbornik Odsjeka za povijesne znanosti Zavoda za povijesne $i$ društvene znanosti Hrvatske akademije znanosti i umjetnosti, 36 (20I7.), $7 \mathrm{I}-84$.

4 "Women have historically been regarded as one of the primary, even formative, audiences for devotional art, so it comes as a surprise that devotional imagery has never been adequately analyzed in terms of gender." JEFFREY F. HAMBURGER, The Visual and the Visionary: Art and Female Spirituality in Late Medieval Germany, New York, Zone Books, I998., I5.

5 Primjerak u Bayerische Staatsbibliothek nosi oznaku ex-libris samostana pustinjačkih augustinaca u Münchenu: „AD BIBLIOTHECAM CONVENTUS MONACENSIS ORD: EREM: SP. AUG:”. 
spominje i predgovor (kao i nakladu): „Diss3 deutsch breuier vō dē ròmischen latàinischē breuier gerechtuertiget vñ auszgezogen mit gůter gemàiner deutsch gedeuschet vnd nach rechter warer ordnung der ròmischen kirchen verordnet vnd. iiij.hundert biecher dedruckt worden auff kosten vnd verlegung desz hochgebornē herren herren Christofferen von frangepan fürst vñ graff zů zeng vỏgel vñ madrusch: mit samp seiner gnaden liebsten gemahel frawen Apollonia."6 Neki od podataka i izraza ponavljaju se i u kolofonu, koji otkriva tiskara-Gregorius de Gregoriis u Veneciji ${ }^{7}$-a dodaje da je prijevod pregledao i korigirao franjevac „Jacob wyg”. ${ }^{8}$ Christine Stöllinger-Löser (r999.) navodi njega kao autora prijevoda i zapaža da se za psaltir i himne poslužio starijim njemačkim prijevodima te da u Brevijar nisu uključeni Marijin oficij i Oficij za mrtve. ${ }^{9}$ Knjižni blok visok je približno 3 o centimetara (in quarto), ima 630 numeriranih listova organiziranih dvostupčano u 38 redaka, tiskan je crvenim i crnim gotičkim slovima i opremljen drvorezima. Dvanaest ih je uz kalendar na početku i prikazuju radove u mjesecima (imenovanima latinski i njemački) te astrolološke znakove. Od jedanaest velikih

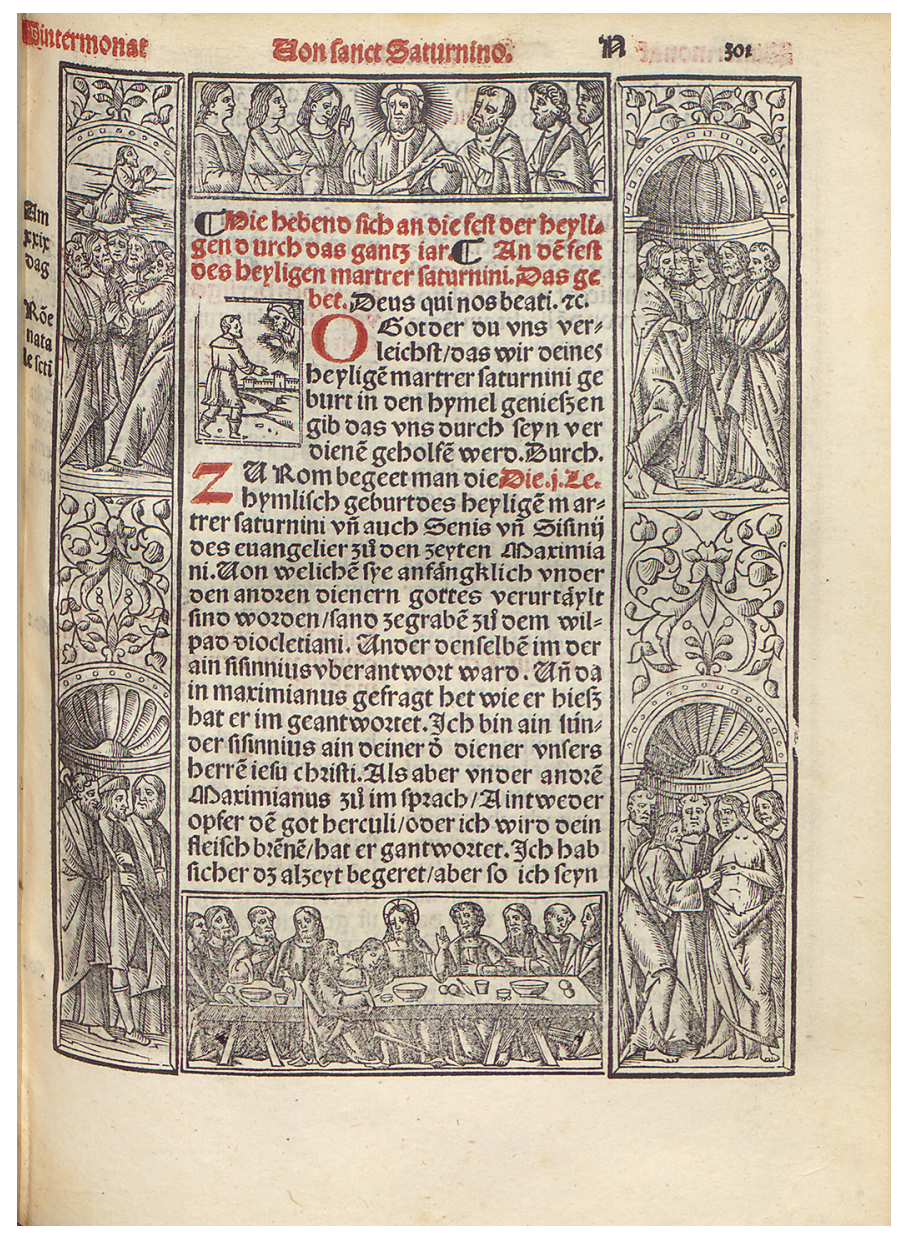

6 Deutsch-römisches Brevier (bilj. I), fol. A2r.

7 Njegov monogram-slova „.G.G.”-nadvišen križem također se javlja na drvorezima (fol. I46r, fol. 246v, fol. 253v). Pietro Zani spominje jedno izdanje Rimskoga rituala iz I520. godine, „ornato di figure in legno disegnate dalle sigle I. A. cioè Joannes Andrea, sopra l'ornato di una cornice evvi la marca G. G. che è la parlante di Gregorius Gregorii, ma essendo la detta marca surmontata da una croce mercantile ci toglie il pensiero di giudicar qualla cornice tagliata dal Gregorj." PIETRO ZANI, Enciclopedia metodica critico-ragionata delle belle arti: parte prima, sv. X, Parma, Tipografia ducale, I822., 284.

8 „Ein end hat das deutsch romisch breuier welliches ausz dē lateinischen rómischē breuier noch rechtem woren gemáinen deutschē (durch kosten dess 3 obgemelten edelen hoch gebornen hern hern Christofel von frangepā Fürst vnd graff zů 3eug Uegel / vñ Madrusch ec. Mit sampt seiner hochberuempten gnadē eelichen gemahel fraw Apollonia wollberuempte aller wirdigiste Gráffin zů Frangepan: gerechtfertiget vñ aus3 $30 g e ̄$ vñ züdrucken verordnet ist). Welliches auch durch dē andechttigē geistlichē brůder Jacob wyg mit barfůser ordens von kolmar mit funderē fleisz gecorigiert / quottiert / vñ in ein solliche ordnūng gesetz ist. Gedruckt vñ sàlicklich̄ē/mit gůtē fleiss 3 vollēdet zů Uenedig durch den erberē meister Gregoriū de gregorijs." Deutsch-römisches Brevier (bilj. I), fol. 629v. Georg Wolfgang Franz Panzer navodi kolofon u kome nije navedena Apolonija, ali je za Jacoba Wyga dodano „Barfußer (sic) ordens”. GEORG WOLFGANG FRANZ PANZER, Annalen der älteren deutschen Literatur, oder, Anzeige und Beschreibung derjenigen Bücher welche von Erfindung der Buchdruckerkunst bis MDXX. in deutscher Sprache gebraucht worden sind, Nürnberg, den Ernst Christoph Gratenauer, I788., 4II.

9 CHRISTINE STÖLLINGER-LÖSER, Wyg, Jakob OFM, u: Die deutsche Literatur des Mittelalters. Verfasserlexikon, 2. izd., X (I999.), I464-I466.

\section{Slika 2}

Ioannes Andrea Vavassore (?), Druorezni okvir s novozavjetnim temama (Isus i apostoli), u: Njemačko-rimski brevijar, Venecija, I518., fol. 3oIr, foto: (c) Nacionalna i sveučilišna knjižnica u Zagrebu, snimili Darko Čižmek i Sonja Hrelja 


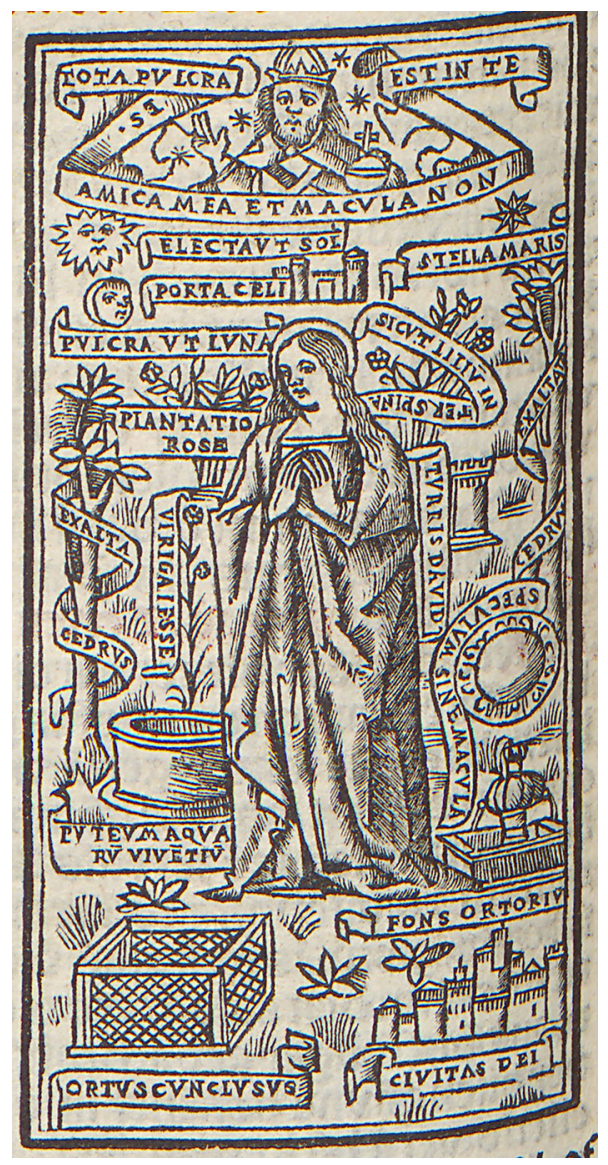

Slika 3

Ioannes Andrea Vavassore (?), Bogorodica s

lauretanskim simbolima, u: Njemačko-rimski brevijar, Venecija, I5I8., fol. 306v,

foto: () Nacionalna i sveučilišna knjižnica u

Zagrebu, snimili Darko Čižmek i Sonja Hrelja 
drvoreza preko cijele stranice pet ih je potpisano „ia” ili „I.A.”, „.3.A.”, na temelju čega su pripisani drvorezbaru i izdavaču Ioannesu (Giovanni; Zoan) Andrei Vavassoreu (Valvassore). Knjižar-izdavač, tipograf, kartograf i drvorezac (djeluje od I5Io. do I572. godine) ${ }_{1}^{10}$ prema nekima je jedna, drugima dvije, a možda i tri osobe. ${ }^{11}$ Od I522. godine javlja se s nadimkom il Guadagnino ili Vadagnino, a stilski utjecaji u njegovim knjižnim ilustracijama kreću se od Dürerovih do Mantegninih inovacija, a šire se i dalje, na renesansnu mletačku skulpturu. Drvorezni okviri za tekst u Brevijaru svjedoče o posebnosti mletačkih likovnih rješenja za knjižni tisak, jer-kako ističe William M. Ivins (I934.)-mletački su drvorezbari, za razliku od onih u drugim europskim gradovima, gdje su slikarstvo i sitnoslikarstvo bili glavni izvor predložaka, zarana bili više pod utjecajem skulpture, a u rješenjima okvira katkada i arhitekture monumentalnih grobnica pa je to postalo jedna od ranih oznaka mletačkih izdanja. ${ }^{12}$ Iako u Brevijaru nema tako monumentalnih rješenja, utjecaj skulpture razabire se i na drvorezima koje Vavassore nije potpisao, ali usporedivi su s drugim njegovim rješenjima (sl. 2). ${ }^{13}$ Osim dvanaest drvoreza složenih kao okvir za tekst, u Brevijar je uključeno i više od dvije stotine manjih drvoreza različitih svetaca te jednostavnih i prepoznatljivih ikonografskih prizora iz Staroga i Novoga zavjeta, ali i jedan složeniji i veći s ikonografskom temom Bogorodice s lauretanskim simbolima i ispisanim zazivima molitve (sl. 3$)^{14}$

Njemačko-rimski brevijar iz I5I8. godine Krste I. Frankapana najraskošnija je frankapanska narudžba u tisku, a s obzirom na likovnu opremu ističe se i među brevijarima iz toga doba uopće.

\section{() (1)}

Knezovi krčki Frankapani kao „začinjavci”: Njemačko-rimski brevijar (I5I8.) Krste I. Frankapana/Sanja Cvetnić/ CC BY / 4.0

DOI: https://doi.org/ıo.3I664/z4khpu.I4
Io Umro je 3I. svibnja I572. ili neposredno prije. Usp. ANNE MARKHAM SCHULZ, Giovanni Andrea Valvassore and his family in four unpublished testaments, $\mathrm{u}$ : Artes atque humaniora: studia Stanislao Mossakowski sexagenario dicata, (ur.) Andrzej Rottermund i dr., Warszawa, Instytut Sztuki Polskiej Akademii Nauk, I998., II7-I25.

II Literatura o Ioannesu Andrei Vavassoreu opsežna je. Atributivne probleme vezane za inačice Vavassoreova potpisa uveli su u literaturu Victor Masséna, duc de Rivoli i Charles Ephrussi (Le Duc de Rivoli [Victor Masséna prince d'Essling], Charles Ephrussi, Zoan Andrea et ses homonymes, u: Gazette des beaux-arts, V-VI, 3 (I89I.), 40I-4I5, 225-244), koji su ga predstavili kao zvijezdu talijanske grafike: „Le nom de Zoan Andrea est un de plus populaires dans l'histoire de la gravure italienne" (40I). Nakon više od stoljeća Vavassoreova slava nije se održala, ali je zanimljiv i dalje kao kartograf i izdavač, a uglavnom je prihvaćen i njegov dug radni vijek. Usp. (i literaturu koju navode) GERT JAN VAN DER SMAN, Print Publishing in Venice in the Second half of the Sixteenth Century, u: Print Quarterly, 3, I7 (2000.), 235-247; CHRISTOPHER L. C. E. WITCOMBE, Copyright in the Renaissance: Prints and the Privilegio in Sixteenth-Century Venice and Rome, Leiden, Brill, 2004., I24-I25 (na obama mjestima naveden je kao Giovanni Andrea Vavassore).

I2 „The early history of the woodcut in practically all other European cities is closely connected with the studios of the painters and miniaturists, but in Venice the early woodcut seems to have been much more a reflection of the local school of sculpture than of its painting. [...] In this the Venetian school was the earliest to show that dependence of black and white upon monumental art which ever since has been the distinguishing mark of the best printed decoration." WILLIAM M. IVINS, Some Venetian Renaissance Woodcut Books, u: The Metropolitan Museum of Art Bulletin, 3, 29 (I934.), 48.

I3 Primjerice, sveci u skupini na prizorima Molitva na Maslinskoj gori, Apostoli u niši, Isus s apostolima u niši i Nevjera su. Tome na fol. 3oIr u Brevijaru iz I5I8. i Sveti Petar sa suecima u Brevijaru iz I524., objavljen u LE DUC DE RIVOLI [VICTOR MASSÉNA PRINCE D'ESSLING], CHARLES EPHRUSSI (bilj. II), 233.

14 Drvorez se nalazi na fol. $306 \mathrm{v}$. 